\title{
Evidence of anaerobic methane oxidation linked with nitrate reduction in a stratified lake using stable isotopes and numerical modeling
}

\author{
ALEJANDRA PENA ${ }^{1}$, FLORIAN EINSIEDL ${ }^{2}$, ANJA \\ WUNDERLICH $^{3}$ AND BERNHARD MAYER ${ }^{4}$ \\ ${ }^{1}$ Technical University Munich \\ ${ }^{2}$ Technische Universität München, Chair of Hydrogeology \\ ${ }^{3}$ Technical University of Munich \\ ${ }^{4}$ University of Calgary \\ Presenting Author: alejandra.pena@tum.de
}

Since the discovery of nitrate/nitrite dependent anaerobic methane oxidation in 2006, evidence has emerged that this process is more widespread in freshwater ecosystems than previously thought. Anaerobic methane oxidation (AOM) coupled with denitrification has been proposed to be a previously overlooked sink of methane in nature. Because this process and its quantitative importance in the environment has been mainly investigated under laboratory conditions, the occurrence and relevance of AOM coupled with denitrification with respect to methane removal in freshwater systems is so far largely unknown.

At the seasonally stratified lake Fohnsee located in Southern Germany, we investigated methane oxidation processes in the water column to determine the dynamics of anaerobic and aerobic methane oxidation throughout nearly one hydrological year. Vertical concentration profiles and corresponding stable isotope data for methane $\left(\delta^{13} \mathrm{C}\right)$ and nitrate $\left(\delta^{15} \mathrm{~N}\right.$ and $\left.\delta^{18} \mathrm{O}\right)$, together with dissolved oxygen concentrations were measured., Subsequently, a numerical model was developed to evaluate whether anaerobic methane oxidation coupled with denitrification is a key biogeochemical process at lake Fohnsee. Our data and the numerical modeling results revealed a seasonally occurring redox zone within the water column where both denitrification and anaerobic methane oxidation appear to be linked. We observed that the anaerobic methane oxidation zone is located near the lake bottom in May, and moved upwards following the seasonal vertical displacement of the oxycline in dependence of the availability of nitrate. This redox dynamic affects the respective contributions of aerobic and anaerobic methane oxidation removing methane from the water column throughout the year. Stable isotope data combined with modelling results revealed that AOM coupled with denitrification is responsible for the removal of approximately $70 \%$ of methane between June and September, and hence, it is the dominant methane sink in the water column during summer stratification of the lake. 